Article

\title{
Statistically Guided Synthesis of MoV-Based Mixed-Oxide Catalysts for Ethane Partial Oxidation
}

\author{
Juan D. Jimenez ${ }^{1, \dagger}$, Kathleen Mingle ${ }^{1, \dagger}$, Teeraya Bureerug ${ }^{2}$, Cun Wen ${ }^{1}$ and \\ Jochen Lauterbach ${ }^{1, *}$ \\ 1 Department of Chemical Engineering, University of South Carolina, Columbia, SC 29208, USA; \\ jiminezj@email.sc.edu (J.D.J.); kmingle92@gmail.com (K.M.); wencun6@gmail.com (C.W.) \\ 2 Department of Chemistry, Mahidol University, Bangkok 10400, Thailand; teeraya.bur@student.mahidol.ac.th \\ * Correspondence: lauteraj@cec.sc.edu; Tel.: +1-803-777-7904 \\ + Authors contributed equally.
}

Received: 15 August 2018; Accepted: 31 August 2018; Published: 2 September 2018

\begin{abstract}
The catalytic performance of $\mathrm{Mo}_{8} \mathrm{~V}_{2} \mathrm{Nb}_{1}$-based mixed-oxide catalysts for ethane partial oxidation is highly sensitive to the doping of elements with redox and acid functionality. Specifically, control over product distributions to ethylene and acetic acid can be afforded via the specific pairing of redox elements $(\mathrm{Pd}, \mathrm{Ni}, \mathrm{Ti})$ and acid elements $(\mathrm{K}, \mathrm{Cs}, \mathrm{Te})$ and the levels at which these elements are doped. The redox element, acid element, redox/acid ratio, and dopant/host ratio were investigated using a three-level, four-factor factorial screening design to establish relationships between catalyst composition, structure, and product distribution for ethane partial oxidation. Results show that the balance between redox and acid functionality and overall dopant level is important for maximizing the formation of each product while maintaining the structural integrity of the host metal oxide. Overall, ethylene yield was maximized for a $\mathrm{Mo}_{8} \mathrm{~V}_{2} \mathrm{Nb}_{1} \mathrm{Ni}_{0.0025} \mathrm{Te}_{0.5}$ composition, while acetic acid yield was maximized for a $\mathrm{Mo}_{8} \mathrm{~V}_{2} \mathrm{Nb}_{1} \mathrm{Ti}_{0.005} \mathrm{Te}_{1}$ catalyst.
\end{abstract}

Keywords: ethane partial oxidation; statistical design of experiments; mixed metal oxides

\section{Introduction}

The catalytic conversion of ethane into olefins and chemicals has been a subject of much research over the past several decades [1,2]. Conversion of ethane into value-added products goes through either ethane deoxyhydrogenation, whose main product is ethylene [3-5], or ethane partial oxidation (EPO), which produces various value-added $C_{2}$ components, such as ethylene [6,7] and acetic acid [8-12]. Currently, the development of efficient heterogeneous catalysts for ethane conversion into their value-added products, acetic acid and ethylene, is of interest due to the abundance of low-cost ethane from shale gas.

State-of-the-art catalysts for the partial oxidation of short alkanes are typically based on molybdenum and vanadium mixed oxides, which have been shown to preferentially form value-added products such as acrylic acid and acetic acid [9,12-20]. Elements such as niobium and antimony have been added to these Mo-V-O structures with the objective of increasing their structural stability and maintaining the desired Mo-V phase [10]. Additionally, the stabilization of the active Mo-V-M-O $(\mathrm{M}=\mathrm{Al}, \mathrm{Co}, \mathrm{Cr}, \mathrm{Fe}$, and $\mathrm{Bi}$ ) phase through interactions between the molybdenum and $\mathrm{M}$ species resulting in the formation of a solid solution during the hydrothermal treatment has been explored as a means of forming a uniform phase [21]. Overall, $\mathrm{Nb}$ was found to be the most effective stabilizing agent for the Mo-V-M-O structure, resulting in the mitigation of phase segregation and increased activity in both ethane partial oxidation $[10,16,22]$ and ethane oxidative dehydrogenation $[20,23]$. 
In addition to studies focused on stabilizing the Mo-V-O catalyst, recent studies have been dedicated to improving the catalytic performance through the incorporation of promoters. Such promoters are typically either acid/base elements, such as tellurium [10,14], calcium, potassium [24], or transition metals with varying redox properties, such as palladium, nickel, and titanium $[3,21,22]$. Optimal loadings of acid/base elements are typically on the same order of magnitude as the loading of niobium into the base catalyst, such as $\mathrm{Mo}_{6} \mathrm{~V}_{2} \mathrm{Te}_{1} \mathrm{O}_{\mathrm{x}}$ and $\mathrm{Mo}_{6} \mathrm{~V}_{2} \mathrm{Sb}_{1} \mathrm{O}_{x}$ [25], where the acid/base elements in this case were tellurium and antimony in place of the niobium. Similarly, in cases where both the niobium and an additional acid/base element is present, their atomic ratio remains at approximate unity, such as $\mathrm{Mo}_{1} \mathrm{~V}_{0.22} \mathrm{Nb}_{0.15} \mathrm{Te}_{0.23}[15,24,26]$. Interestingly, in some cases the destabilization of the primary Mo-V-O phase has not resulted in decreased catalytic activity, possibly due to the formation of new active sites in lieu of the Mo-V-O phase. One such example is the incorporation of small amounts of alkali metals such as potassium, or basic metals such as bismuth, to MoVTeNbO [24]. Due to extensive segregation of the crystalline structure of mixed-oxide catalysts upon addition of dopants, forming a clear correlation between catalyst structure, dopants, and performance is currently challenging when comparing the varied literature $[24,27-30]$.

Contrary to findings for acid-element doping, optimal loadings of redox elements vary based on the reducibility of the metal. For example, incorporating noble metals such as palladium dramatically affects the catalytic activity to favor acetic acid production with the addition of only $0.0025 \mathrm{wt} \%$ $\mathrm{Pd}$ metal to a $\mathrm{Mo}_{0.61} \mathrm{~V}_{0.31} \mathrm{Nb}_{0.08} \mathrm{O}_{x} / \mathrm{TiO}_{2}$ catalyst [12]. However, less reducible transition metals, such as nickel and titanium, appear to require higher loadings to have a comparable effect on activity, where optimal ethylene production was achieved using a $\mathrm{Ni}_{0.85} \mathrm{Nb}_{0.15} \mathrm{O}_{x}$ catalyst [31] and high acetic acid production was achieved using a $\mathrm{Mo}_{6} \mathrm{~V}_{2} \mathrm{Al}_{1} \mathrm{Ti}_{0.5} \mathrm{O}_{x}$ catalyst [19]. While the doping of acid/base elements into Mo-V-O structures has been addressed in depth in several studies [32-34], a comprehensive understanding of how co-incorporating both reducible and acidic species at varying levels affects both catalytic activity and structure; specifically, the required balance between reducibility and acidity remains unclear.

This work is focused on addressing the effects of adding acid and redox elements in various ratios to elucidate their coupled effects on both ethane partial oxidation and their structural properties to gain insight into the origins of enhanced activity. To guide this work, a statistical Design of Experiments (DOE) was employed to screen a three-level four-factor $\left(3^{4}\right)$ full factorial design space of distinct catalyst formulations based on doping a $\mathrm{Mo}_{8} \mathrm{~V}_{2} \mathrm{Nb}_{1}$ catalyst. A hydrothermal synthesis method was used to prepare the desired Mo-V-O mixed-oxide crystalline structure. The parameters explored include: transition metal redox element $(\mathrm{Pd}, \mathrm{Ni}$, and $\mathrm{Ti})$ doped, acid/base element $(\mathrm{K}, \mathrm{Cs}$, and $\mathrm{Te})$ doped, the ratio between the redox and acid/base element $(0.005,0.5$, and 1.0$)$, and the total dopant added relative to the niobium content of the base catalyst $(0.005,0.5$, and 1.0$)$. By systematically adjusting the acidity and reducibility of the catalyst across a range of elemental combinations, we can draw statistically significant conclusions on the coupled effects of doping $\mathrm{Mo}_{8} \mathrm{~V}_{2} \mathrm{Nb}_{1}$ mixed-oxide catalysts with elements of varied redox and acid functionality on the catalytic performance in ethane partial oxidation and the corresponding changes in crystalline structure.

\section{Results and Discussion}

\subsection{Synthesis of Doped $\mathrm{Mo}_{8} \mathrm{~V}_{2} \mathrm{Nb}_{1} \mathrm{O}_{x}$ Catalysts}

The formation of a uniform solid solution of the Mo-V-O oxide has been widely reported to lead to the preferential oxidation of alkanes to olefins and acids $[15,35,36]$. In contrast to conventional mixtures of molybdenum- and vanadium-based oxides, which give rise to multiple oxide phases due to phase segregation, the high dispersion of the vanadium in the Mo-V-O complex can be achieved via the formation of a solid solution $[15,18,19,21,25]$. Furthermore, the Mo-V-O complex allows for the incorporation of stabilization agents and promoters [29,30,33]. Niobium has been reported as a stabilizing agent in the Mo-V-O structure, helping keep the vanadium and molybdenum species 
stable throughout the reaction $[8,16-18]$ by facilitating their redox cycles. The solid solution is due to the formation of an Anderson-type complex, which is formed upon mixing the molybdenum and niobium precursors to create a $\left(\mathrm{NH}_{4}\right)_{3} \mathrm{NbMo}_{6} \mathrm{H}_{6} \mathrm{O}_{24}$ complex $[19,25,37]$. The Anderson-type complex then readily reacts with $\mathrm{VOSO}_{4}$ to form the $\mathrm{Mo}-\mathrm{V}-\mathrm{M}-\mathrm{O}$ structure, where $\mathrm{M}$ here is niobium, and form a solid solution with no observable phase segregation of the individual oxide phases.

A composition of $\mathrm{Mo}_{8} \mathrm{~V}_{2} \mathrm{Nb}_{1}$ was chosen as the base catalyst due its high selectivity towards acetic acid and ethylene during EPO [12,16]. Additionally, the excess molybdenum in the synthesis gel, where the Anderson-type complex requires a stoichiometry of six to one $\mathrm{Mo:Nb}$, serves to accommodate the addition of dopants into the base $\mathrm{Mo}_{8} \mathrm{~V}_{2} \mathrm{Nb}_{1}$ structure. The dopants for this work were chosen to probe the relationship between surface acidity and reducibility and EPO-product distribution $[9,22,38]$. In this study, the reducible metals chosen included palladium, nickel, and titanium. Each of these dopants varies in terms of their reducibility, with palladium being the most reducible and titanium being the least. Additionally, these metals have been shown to promote EPO to favor the production of ethylene or acetic acid, both being target products for this system. Palladium is one of the most studied promoters for this system due to its ability to preferentially form acetic acid via an acetaldehyde intermediate $[12,17,22,39,40]$. Titanium has been chosen as a redox element due to its support interaction effects for EPO [18,39], while nickel has been shown to preferentially form ethylene [31,41-43] for various distinct catalytic systems. In a similar manner, the surface acidity was adjusted by introducing potassium, cesium, or tellurium to the catalyst precursor. These elements were chosen to cover a range of acidities, where potassium represents a typical alkali group metal of nominal acidity and cesium represents a much stronger acid. Tellurium was chosen as the third acid/base component due to its overwhelming precedence in catalyzing EPO to promote greater catalytic activity and the more selective formation of acetic acid [14,23,26,37,44]. It is important to note that, while tellurium can contribute catalytic activity via its redox cycling between the +4 and +6 state, its contribution to the overall reducibility of the catalyst is significantly lower than the chosen redox elements for this study; warranting categorization as an acid/base element in this study and not a redox element.

To address mixed findings in the literature over the effect of the surface acidity and reducibility balance, we systematically varied the redox/acid element ratio between the acid elements and the redox elements to various degrees. Since the redox elements tend to affect catalytic activity largely by electronic effects caused by the electron orbital overlap from the $d$-shells of the transition metals, typically only small amounts of these elements are required to significantly change the catalytic activity. Conversely, acids affect catalytic activity by changing the surface acidity, where an effect on catalytic activity is generally only observed at higher doping levels.

\subsection{Design of Experiment-Parameter Space}

To explore all possible combinations between redox elements and acid elements, we created 81 distinct catalyst formulations by adding nine unique dopant pairs to the base $\mathrm{Mo}_{8} \mathrm{~V}_{2} \mathrm{Nb}_{1}$ catalyst, and synthesizing catalysts, including each dopant pair, at nine distinct loadings. Dopant pairs included the following: PdK, PdCs, PdTe, NiK, NiCs, NiTe, TiK, TiCs, and TiTe. The balance between redox and acid functionality was tailored by varying the redox to acid (R/A) ratio and the total amount of dopant added was varied with the dopant to host $(\mathrm{D} / \mathrm{H})$ ratio, where each were treated as numerical variables ranging from $0.005,0.5$, and 1.0, as summarized in Table 1 . The addition of dopants at different levels can yield varied effects, ranging from predominantly electronic interactions at low $\mathrm{D} / \mathrm{H}$ ratios to phase segregation of the dopant species and possible formation of new active sites at high $\mathrm{D} / \mathrm{H}$ ratios. The wide range of dopant/host ratios screened was intended to cover the range of these possible effects. Elemental ratios were relative to the niobium loading of the base catalyst $(\mathrm{Nb}=1)$, where the sum of the both redox and acid species totals to either a D/H ratio of $0.005,0.5$, or 1.0. For illustration, a D/H and R/A ratio of 1.0 corresponds to a composition of $\mathrm{Mo}_{8} \mathrm{~V}_{2} \mathrm{Nb}_{1} \mathrm{Ni}_{0.5} \mathrm{Te}_{0.5}$. 
Table 1. Parameter space for three-level four-factor full factorial design $\left(3^{4}\right)$.

\begin{tabular}{ccccc}
\hline Factor & Variable Type & Low & Center Point & High \\
\hline A: Redox element (R) & Categorical & $\mathrm{Pd}$ & $\mathrm{Ni}$ & $\mathrm{Ti}$ \\
B: Acid/base element (A) & Categorical & $\mathrm{K}$ & $\mathrm{Cs}$ & $\mathrm{Te}$ \\
C: Dopant to Host ratio (D/H) & Numerical & 0.005 & 0.5 & 1.0 \\
\hline D: Redox to acid ratio (R/A) & Numerical & 0.005 & 0.5 & 1.0 \\
\hline
\end{tabular}

Catalyst composition: $\mathrm{Mo}_{8} \mathrm{~V}_{2} \mathrm{Nb}_{(1=\mathrm{H})}\left[\mathbf{R}_{\mathbf{R}} \mathbf{A}_{\mathbf{A}}\right]_{\mathbf{D}}$.

\subsection{Energy Dispersive X-ray Spectroscopy (EDS) Elemental Uptake Analysis}

The hydrothermal synthesis method employed here proceeds through the formation of an Anderson-type heteromolybdate intermediate for which the possibility of incomplete element uptake exists $[26,27,45]$. Variation in elemental composition over the design space was accomplished by varying the R/A and the D/H ratio. Energy Dispersive X-ray Spectroscopy (EDS) was used to probe both intended and unintended variation in the loadings of catalyst components. Analysis of the EDS data was focused on perturbations to the base structure as evidenced by the measured vanadium and niobium contents. It should be noted that nominal loadings for the 81 catalysts were expected to fall in the following compositional range: $\mathrm{Mo}_{8} \mathrm{~V}_{2} \mathrm{Nb}_{1} \mathrm{R}_{0.000025-0.5} \mathrm{~A}_{0.0025-1}$. Over the 81 samples studied, atomic loadings for the $\mathrm{Mo}_{8} \mathrm{~V}_{2} \mathrm{Nb}_{1}$ base composition were found to range from $1.28 \pm 0.1$ to $3.33 \pm 0.84$ for vanadium, and $0.69 \pm 0.12$ to $1.17 \pm 0.05$ for niobium. While some of this variance can be ascribed to an EDS measurement error, certain relationships between the base catalyst uptake and the catalyst design variables were found to be statistically significant. For instance, uptake of both vanadium and niobium into the structure were negatively correlated with an increased $\mathrm{D} / \mathrm{H}$ ratio, meaning that, to some extent, the dopants displaced the $\mathrm{V}$ and $\mathrm{Nb}$ from the material. It should be noted that this effect was more pronounced in the case of $\mathrm{Nb}$, with $\mathrm{Nb}$ uptake being almost $10 \%$ less when $\mathrm{D} / \mathrm{H}$ was increased from 0.005 to 1 . This effect was also much more significant when the elements being doped were primarily redox elements (i.e., high R/A ratio), as shown in Figure 1. This suggests that the redox elements were able to displace the niobium in part from the channels of the base structure.

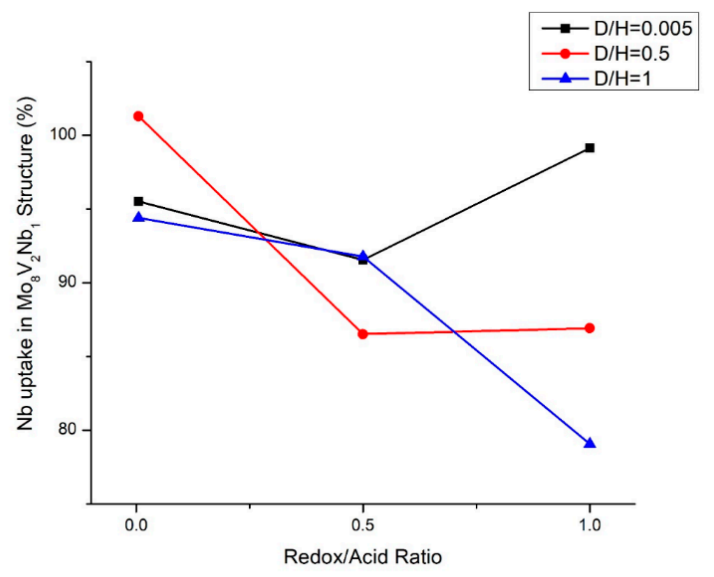

Figure 1. Effect of dopant levels on $\mathrm{Nb}$ uptake in MoVNb-based catalysts.

Additionally, some sensitivity was found in terms of $\mathrm{Nb}$ and $\mathrm{V}$ uptake with respect to the specific redox and acid elements doped. The $\mathrm{V}$ uptake was found to be particularly sensitive to the doping of redox elements, being the lowest when $\mathrm{Pd}$ was doped, while the $\mathrm{Nb}$ uptake was sensitive to both redox and acid doping, with the lowest uptakes corresponding to Ti and Te doping. In general, the least amount of disturbance to the base structure was achieved when balanced levels of redox and acid elements were doped $(\mathrm{R} / \mathrm{A}=1)$, and the greatest amount of disturbance was found at the highest 
doping levels $(\mathrm{D} / \mathrm{H}=1)$. Additionally, an interaction between the $\mathrm{R} / \mathrm{A}$ ratio and $\mathrm{D} / \mathrm{H}$ ratio was observed where increasing the $\mathrm{D} / \mathrm{H}$ ratio only caused significant changes to the base structure for high levels of redox element loading $(\mathrm{R} / \mathrm{A}=1)$. This indicates that acid/base elements were more easily incorporated into the base structure than redox elements. Overall, it was found that increasing or decreasing $\mathrm{D} / \mathrm{H}$ and $\mathrm{R} / \mathrm{A}$ ratios yielded the intended variations in dopant loadings.

\subsection{Crystalline Structure of Doped $\mathrm{Mo}_{8} \mathrm{~V}_{2} \mathrm{Nb}_{1} \mathrm{O}_{x}$ Catalysts}

The crystalline structure of the redox and acid/base element-doped MoVNb catalysts was studied for all samples using powder X-ray diffraction (XRD). The hydrothermally synthesized base $\mathrm{MoVNb}$ catalyst, shown in Figure 2, showed the Mo-V-O mixed-oxide phase hallmarked by sharp $22^{\circ}$ and $45^{\circ}$ (001) reflections and a broad $27^{\circ}$ reflection. Based on the literature [19-21,27], this Mo-V-O structure is ascribed to a slablike structure comprised of both ordered and disordered crystallographic directions. Additional peaks could be ascribed to $\mathrm{MoO}_{3}, \mathrm{Mo}_{6} \mathrm{~V}_{9} \mathrm{O}_{40}$, and /or $\mathrm{Mo}_{3} \mathrm{Nb}_{2} \mathrm{O}_{11}[16,28,32,46]$. To understand the influence of the redox and acid/base dopants, as well as their relative and overall doping levels, differences between the hydrothermally prepared base $\mathrm{MoVNb}$ and doped $\mathrm{MoVNb}$ catalysts were studied.

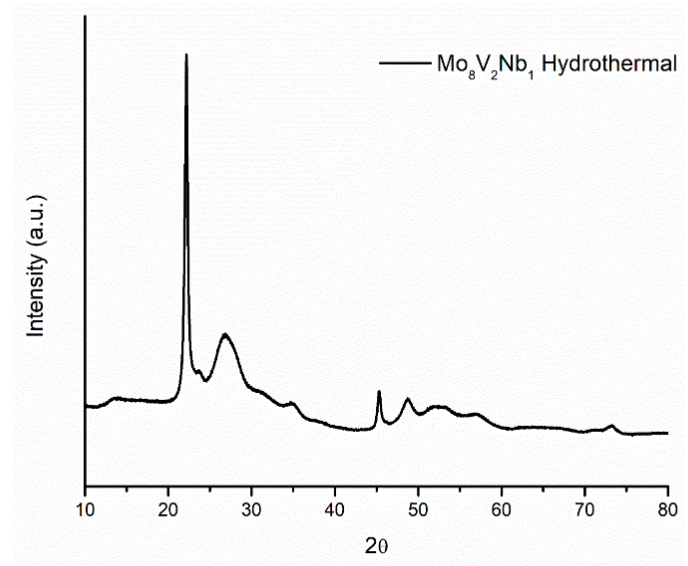

Figure 2. X-ray diffraction (XRD) pattern of hydrothermally prepared base $\mathrm{MoVNbO}_{x}$ catalyst.

The analysis of the XRD data focused on both the position and the Full-Width Half-Maximum (FWHM) of the main $22^{\circ}$ peak to calculate the d-spacing and grain size of the Mo-V oxide, where this peak is correlated to the crystallographic structure denoted as the "M1 phase" in the literature $[20,28,46]$. Additionally, crystal faceting of the primary slablike Mo-V-O phase was analyzed by measuring the intensity ratio between the sharp $22^{\circ}$ peak, showing the ordered crystallographic growth direction, and the disordered amorphous peak at $27^{\circ}$. The correlation between the intensity of the $22^{\circ}$ reflection and the specific activity for ethane oxydehydrogenation (ODH) has been proposed as an indicator for the preferential formation of olefins or oxygenates in the Mo-V system [20]. Additionally, it was found that secondary phases were formed on top of the base Mo-V-O structure when doped with certain redox and acid/base elements at varying levels. The identity of these secondary phases are assorted Mo- and V-based oxides of different stoichiometry as well as, in a few cases, reflections from small particles of segregated oxides of redox/acid/base dopants. While exhaustive structural resolution of each design point was out of the scope of this study, the conditions under which secondary-phase formation occurred were noted and relative intensities between the main reflection and the most intense peak arising from secondary phases were calculated to indicate the relative volume of the catalyst involved in secondary-phase formation.

First, the d-spacing of the mixed-oxide indicated by the peak location of the $22^{\circ}$ reflection $(d=4.01 \AA)$ was tracked for each sample as a possible gauge for dopant incorporation directly into the mixed-oxide lattice $[46,47]$. In such a situation an increase in d-spacing (evidenced by a peak shift 
to lower $2 \theta$ ) would be expected, since most dopant elements have large radius compared with Mo, $\mathrm{V}$ and $\mathrm{Nb}$. It was found, however, that the d-spacings of the $22^{\circ}$ reflection for the doped samples only ranged from 3.98 to 4.02 . This small range of $d$-spacings supports the conclusion that the various redox and acid/base dopants investigated were not actually incorporated directly into the mixed-oxide lattice and most likely reside in the six- and seven-membered rings formed by the Mo-V-O structure, where these vacancies allow for the insertion of atoms [32].

The grain sizes calculated via Scherrer's equation from the FWHM of $22^{\circ}$ peak of the doped $\mathrm{MoVNb}$ samples were found to be sensitive to both the type of dopants and the levels studied. These parameters were investigated to understand how different doping levels could change the active surface area and/or redox properties of the catalysts; effects which may be expected to accompany a change in Mo-V-O grain size. The grain size of the base MoVNb material, calculated using the broadening of the $22^{\circ}$ peak according to Scherrer's equation $[48,49]$, was $22 \mathrm{~nm}$. Identical analysis of the doped $\mathrm{MoVNb}$ catalysts showed that the range of grain sizes was $12.4-35.0 \mathrm{~nm}$, depending on the design levels employed. Statistical analysis of the relationship between doping elements and levels with grain size revealed that the most important factors for controlling grain size were the type of redox element and the $\mathrm{D} / \mathrm{H}$ ratio, as well as the interaction between the two. It was found that doping with $\mathrm{Ni}$ increased grain size most significantly, while Ti yielded grain sizes that were smaller and, on average, identical to that of the base $\mathrm{MoVNb}$ oxide. In general, increasing dopant levels had the effect of decreasing grain sizes, but at the lowest level of $\mathrm{D} / \mathrm{H}=0.005$, no notable difference could be seen between the grain sizes when $\mathrm{Pd}, \mathrm{Ni}$, or Ti was doped. In an analogous manner, differences between grain sizes of $\mathrm{Pd}-, \mathrm{Ni}$-, and Ti-doped materials were only apparent at R/A ratios of 0.5 or greater. These interactions simply indicate that the different behavior of redox elements with respect to grain size were not apparent under the conditions where the redox elements were doped in the smallest amounts (i.e., small $\mathrm{D} / \mathrm{H}$ and $\mathrm{R} / \mathrm{A}$ ratios). The observation of decreased grain sizes at higher dopant levels, as can be seen for the MoVNbNiCs family of catalysts at the R/A $=0.5$ level in Figure 3 , leads to the question of whether one of the effects of the redox dopant is to impede the crystal growth of the primary mixed-oxide phase.

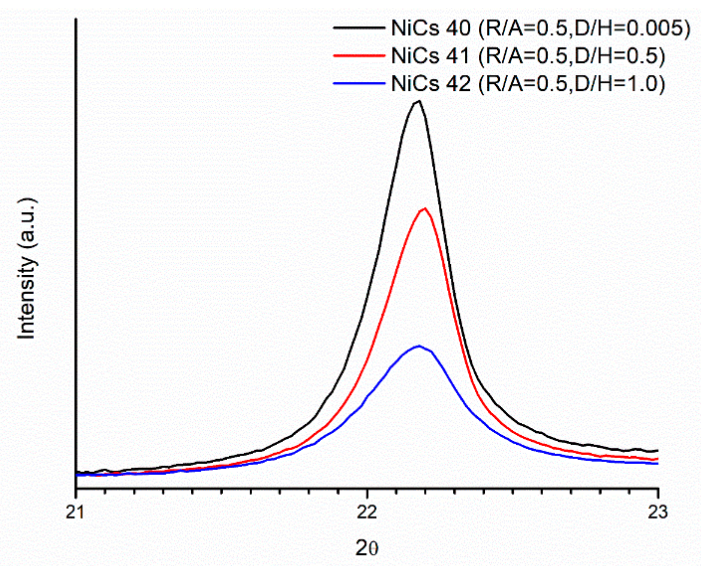

Figure 3. XRD grain size differences for MoVNbNiCs at varied dopant levels.

The relative intensity of the ordered $22^{\circ}$ reflection scaled to the intensity of the disordered $27^{\circ}$ reflection was investigated as an indication of ordered preferential growth. For convenience, this will be referred to as the primary-phase intensity ratio (PPIR). The base formulation of $\mathrm{MoVNb}$ was found to have a PPIR of 3.41. R/A and D/H ratios were found to affect the PPIR significantly, with increasing each having the effect of decreasing the PPIR. It was also found that the significance of the effect of changing the $\mathrm{D} / \mathrm{H}$ ratio was most apparent at the low $\mathrm{R} / \mathrm{A}$ level of 0.005 . In practice, this means that the highest PPIR values, and the only values that were greater than the base catalyst PPIR, occurred for catalysts with both low overall dopant levels and high relative levels of acid/base dopant 
$(\mathrm{D} / \mathrm{H}=\mathrm{R} / \mathrm{A}=0.005)$, as shown in Figure 4. Interestingly, the redox and acid/base elements doped were found to have virtually no effect on this measurement, meaning that nearly identical trends held for all redox-acid/base pairs were studied.

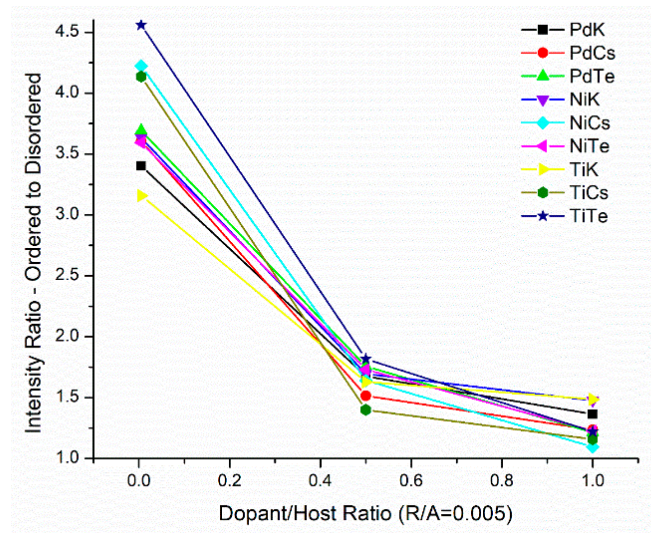

Figure 4. XRD primary-phase intensity ratio variations with dopant level.

The final structural descriptor studied via XRD analysis was the formation and relative volume of secondary phases. This variable is important in understanding trends in activity due to its direct relation to the abundance of the active Mo-V-O phase. This will be defined as the secondary-phase intensity ratio (SPIR); the XRD intensity ratio between the largest secondary phase peak and the largest Mo-V-O primary phase peak was at $22^{\circ} 2 \theta$. While the doped redox element, particularly when the element was Pd, affected the occurrence of secondary phases, it had no significant effect on the SPIR. The SPIR was found to be mostly sensitive to the type of acid/base element doped as well as the R/A and $\mathrm{D} / \mathrm{H}$ ratios. Specifically, it was found that doping with Cs at an R/A level of 0.005 yielded the highest SPIRs, and this effect was increasingly apparent at higher $\mathrm{D} / \mathrm{H}$ ratios. The effect of increased SPIR with decreased $\mathrm{R} / \mathrm{A}$ ratio and increased $\mathrm{D} / \mathrm{H}$ ratio held for other redox-acid/base pairings as well, but at a much smaller magnitude. The effect of secondary-phase formation when Cs was doped is illustrated in Figure 5.

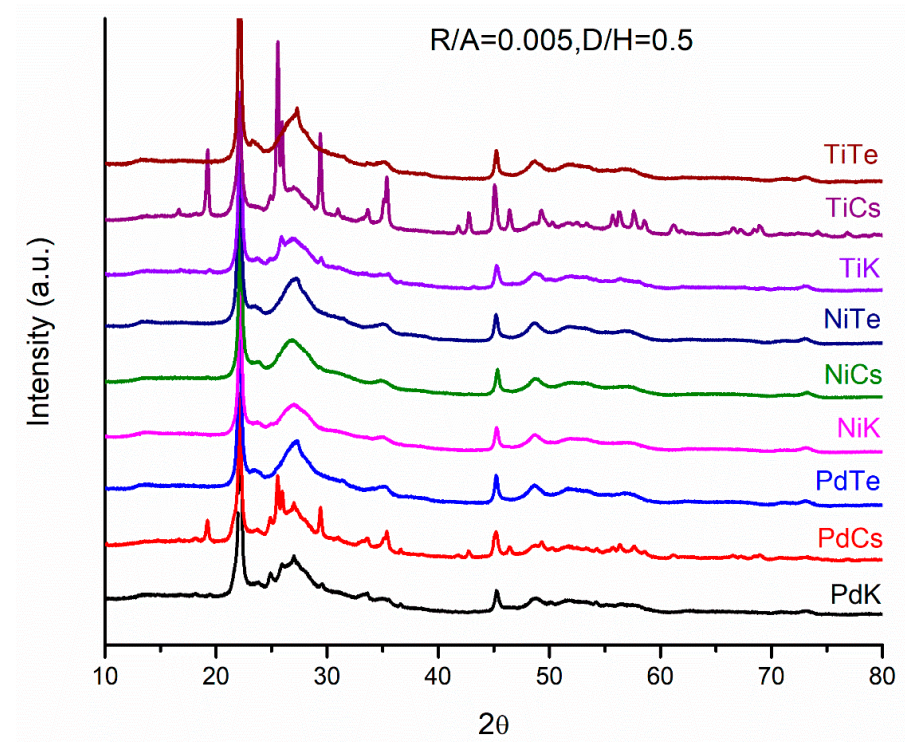

Figure 5. XRD secondary-phase formation in selected samples $(\mathrm{R} / \mathrm{A}=0.005$ and $\mathrm{D} / \mathrm{H}=0.5)$. 


\subsection{Ethane Partial Oxidation}

\subsubsection{Ethane Partial Oxidation on Doped $\mathrm{Mo}_{8} \mathrm{~V}_{2} \mathrm{Nb}_{1}$ Catalysts}

The catalytic evaluation of the catalyst compositions guided by the statistical design were carried out in a temperature range of $120-460^{\circ} \mathrm{C}$ with a fixed ethane to oxygen ratio of $4: 5$. As the product distribution of the EPO reaction has been shown to be highly sensitive to residence time and temperature, space velocity and temperature optimization was carried out for the base catalyst composition to maximize the production of acetic acid, shown in Figure 6. The base catalyst with a composition of $\mathrm{Mo}_{8} \mathrm{~V}_{2} \mathrm{Nb}_{1}$ has been previously reported to produce optimal acetic acid yield $[9,10,17]$, which is consistent with our experimental findings. The optimal temperature and space velocity for acetic acid selectivity were found to be $450{ }^{\circ} \mathrm{C} \pm 10^{\circ} \mathrm{C}$ and $1200 \mathrm{~h}^{-1}$, respectively. These conditions were used in the analysis of the DOE, which is summarized in Figure 7, showing the selectivity towards each product. Due to the fact the product distribution is highly dependent on residence time, where a slight change in residence time shifts the product distribution to favor ethylene, the catalysts were compared at different conversions with all other relevant variables held constant.

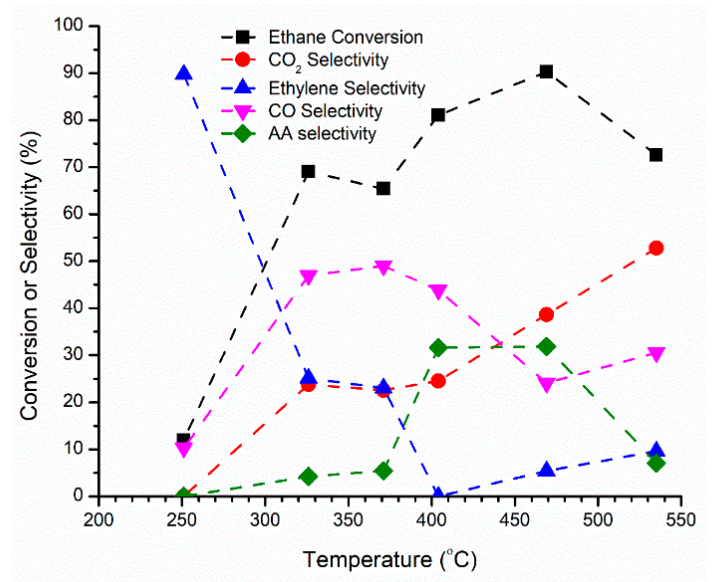

Figure 6. Ethane partial oxidation over base $\mathrm{Mo}_{8} \mathrm{~V}_{2} \mathrm{Nb}_{1}$ catalyst. Reaction conditions: $1200 \mathrm{~h}^{-1}$, atmospheric pressure.

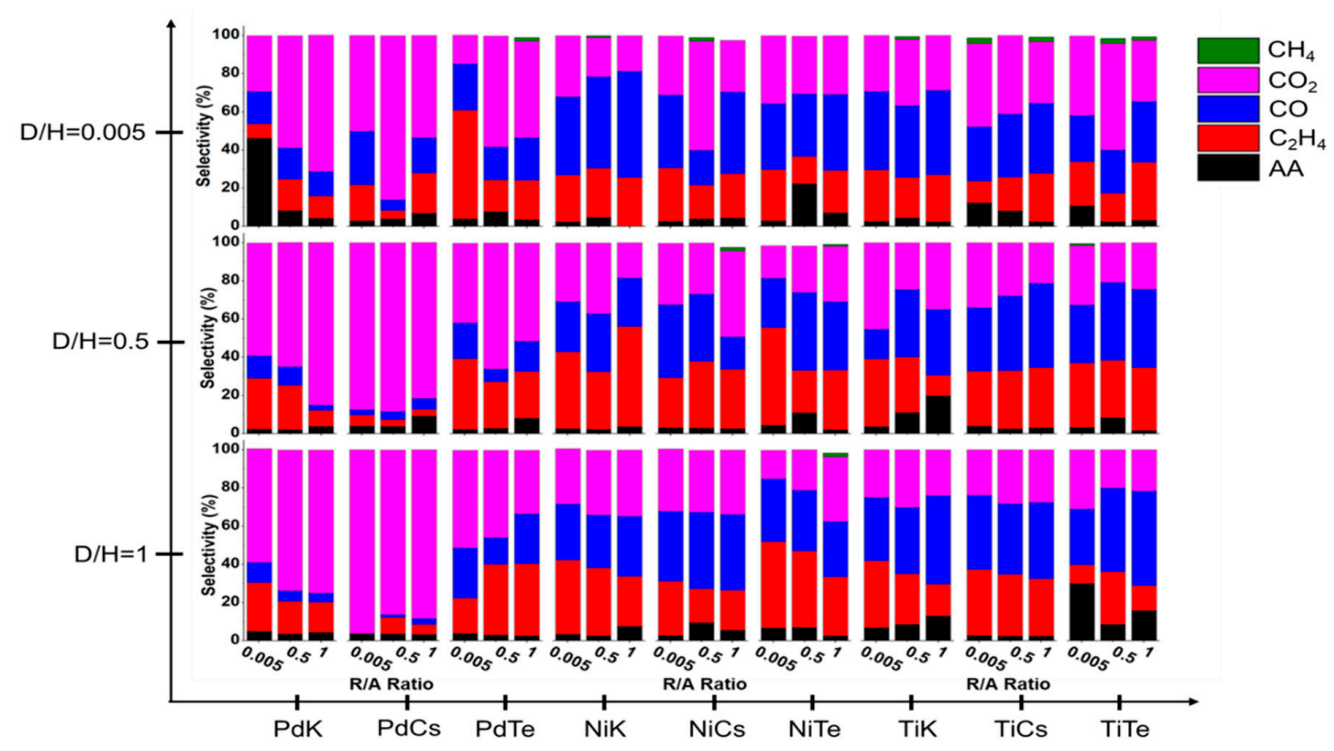

Figure 7. Ethane partial oxidation product distribution at $450{ }^{\circ} \mathrm{C}, 1 \mathrm{~atm}$, and $1200 \mathrm{~h}^{-1}$. 
The product distribution at $450{ }^{\circ} \mathrm{C}$ for all 81 doped $\mathrm{Mo}_{8} \mathrm{~V}_{2} \mathrm{Nb}_{1} \mathrm{O}_{x}$ catalysts is shown in Figure 7 . Design of experiments was used to elucidate statistically significant relationships between design levels and product distribution. The analysis of effects relevant to the catalytic activity is highlighted in Table 2, which shows the trends across the different redox and acid/base elements, the $\mathrm{D} / \mathrm{H}$ ratio, and the R/A ratio. A main conclusion from this analysis is that each variable investigated-redox element, acid/base element, redox/acid ratio, and dopant/host ratio-had significant effects on ethane conversion and product distribution. Furthermore, the effects of external mass transfer limitations were explored by reproducing catalytic activity with varying catalyst mesh sizes, where the same catalyst composition with a mesh size $<125 \mu \mathrm{m}$ performed identical to the same composition with a mesh size of 500-400 $\mu \mathrm{m}$ in both the differential conversion regime and the high conversion regime, as shown in Figure S1.

Table 2. Summary of Design of Experiments (DOE) main effects.

\begin{tabular}{cccccc}
\hline Factor & $\begin{array}{c}\text { Ethane } \\
\text { Conversion }\end{array}$ & $\begin{array}{c}\text { Ethene } \\
\text { Selectivity }\end{array}$ & $\begin{array}{c}\text { Acetic Acid } \\
\text { Selectivity }\end{array}$ & $\begin{array}{c}\text { Secondary-Phase } \\
\text { Abundance }\end{array}$ & Grain Size \\
\hline Redox element & $\mathrm{Ti}>\mathrm{Ni}>>\mathrm{Pd}$ & $\mathrm{Ni}>\mathrm{Ti}>>\mathrm{Pd}$ & $\mathrm{Ti}>\mathrm{Pd}>\mathrm{Ni}$ & $\mathrm{No} \mathrm{effect}$ & $\mathrm{Ni}>\mathrm{Pd}>\mathrm{Ti}$ \\
Acid/base element & $\mathrm{Te}>\mathrm{K}>\mathrm{Cs}$ & $\mathrm{Te}>\mathrm{K}>\mathrm{Cs}$ & $\mathrm{K}=\mathrm{Te}>\mathrm{Cs}$ & $\mathrm{Cs}>\mathrm{Te}>\mathrm{K}$ & No effect \\
Redox/acid ratio & No effect & 0.005 optimal & 0.005 optimal & Decreases & No effect \\
Dopant/host ratio & 1 optimal & 0.5 optimal & 0.005 optimal & Increases & Decreases \\
\hline
\end{tabular}

\subsubsection{Effect of Doping $\mathrm{Mo}_{8} \mathrm{~V}_{2} \mathrm{Nb}_{1} \mathrm{O}_{x}$ on EPO Product Distribution}

The single most important variable investigated for optimizing ethylene selectivity was the redox element used, with a significant sensitivity to the acid element co-employed. Ethylene selectivity, on the one hand, can be increased considerably by doping with PdTe rather than PdCs, which was detrimental to ethylene formation. Conversely, product distribution was largely insensitive to the acid dopant when the redox element being doped was Ti. Overall, ethylene selectivity was maximized by doping with NiTe at a D/H level of 0.5 and a R/A level of 0.005 . Acetic acid selectivity, on the other hand, was optimized by doping MoVNb with TiK or TiTe at low $\mathrm{R} / \mathrm{A}$ and $\mathrm{D} / \mathrm{H}$ levels $(\mathrm{D} / \mathrm{H}=\mathrm{R} / \mathrm{A}=0.005)$ but showed a high level of sensitivity to interactions between the parameters investigated. The most important relationship found was between the redox element, the acid/base element, and the $\mathrm{D} / \mathrm{H}$ ratio, as illustrated in Figure 8. Acetic acid (AA) selectivity was optimized at very low dopant levels $(\mathrm{D} / \mathrm{H}=0.005)$ for PdK and NiTe dopant pairs, whereas a large dopant level $(\mathrm{D} / \mathrm{H}=1)$ optimized AA selectivity for the TiTe dopant pair, with these compositions performing remarkably better than other redox-acid dopant pairs at equivalent $\mathrm{D} / \mathrm{H}$ levels. It also should be noted that the optimum acid dopant pair for Ti was different at each D/H level studied.
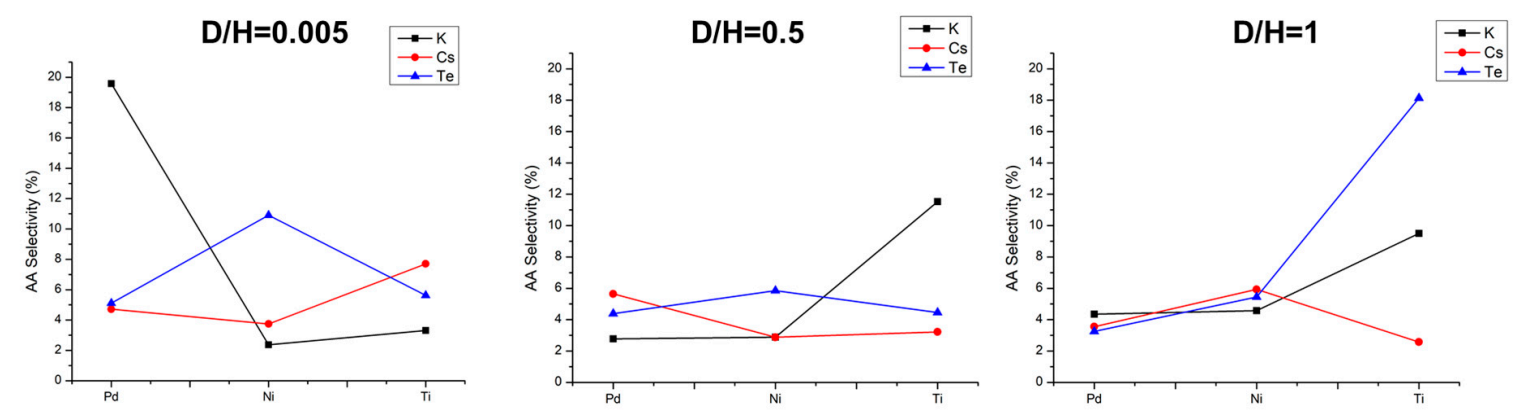

Figure 8. Interaction between redox element, acid element, and D/H level for AA selectivity.

A low R/A ratio of 0.005 was found to be favorable for both ethylene and acetic acid selectivity, indicating that in both cases an excess of acid/base dopant is needed relative to the redox dopant. 
This is consistent with the literature, where the incorporation of acid/base elements at an atomic ratio of $\sim 2: 1$ between $V$ and the acid/base element has been shown to result in the increased formation of value-added products in partial oxidation reactions $[13,15,38]$. Surface acidity is thought to play a large role in product selectivity, where acid sites promote the formation and subsequent desorption of acetic acid, while ethylene preferentially forms and desorbs on reducible sites $[9,50]$, such as those found on the redox elements. However, in this case, it was found that acid sites were also necessary for the formation of ethylene. The role of surface acidity also extends to other catalytic systems for the conversion of ethane into value-added products, where in the oxidative dehydrogenation of ethane, the inclusion of highly basic metals such as platinum leads to increased selectivity towards ethylene [4,6]. It is well-known that dopant effects can considerably affect catalytic activity when doping with transition metals due to the electronic interactions between the metals and the host oxide structure $[6,8,12,17,22,31]$.

Two distinct mechanisms are possible in the partial oxidation of ethane into ethylene and AA. The first possibility is the direct oxidation of ethane via a $\mathrm{CH}_{3} \mathrm{CH}_{2} \mathrm{O}^{*}$ intermediate species followed by the subsequent oxidation to acetic acid $[1,11,16,51]$; the second is the oxidation of an adsorbed ethylene species through a Wacker mechanism involving a surface X-O site that reacts with water to form a X-OHOH site capable of converting ethylene to AA [9,22]. In our findings, an increase in AA formation was generally coupled with an immediate decrease in ethylene, suggesting that AA was forming mainly through the oxidation of readsorbed ethylene via the Wacker mechanism. However, the possibility of parallel pathways cannot be ruled out entirely as the products were often coproduced.

\subsubsection{Effect of Doped $\mathrm{Mo}_{8} \mathrm{~V}_{2} \mathrm{Nb}_{1}$ Structure on Catalytic Activity}

While a small R/A ratio being favorable for both acetic acid and ethylene formation can be attributed in part to an excess of surface acidity necessary relative to redox properties, it should be noted that small R/A levels were highly correlated with high PPIRs introduced previously. In fact, at the low $\mathrm{D} / \mathrm{H}$ and low $\mathrm{R} / \mathrm{A}$ pairing, the PPIR was as much as four times greater than its value at other $\mathrm{D} / \mathrm{H}$ and $\mathrm{R} / \mathrm{A}$ combinations. This is consistent with observations of increased ethane-oxidation activity at higher intensity ratios reported previously [20]. It follows that, in addition to creating favorable surface acid properties for reactivity, an excess of acid dopant could play a role in extending the aspect ratio of the slablike structure of the primary active Mo-V-O phase indicated by the PPIR.

On the other hand, smaller $\mathrm{D} / \mathrm{H}$ levels $(\mathrm{D} / \mathrm{H}=0.005)$ were preferable for acetic acid formation, while intermediate levels were optimum for ethylene formation $(D / H=0.5)$. It should be noted that high $\mathrm{D} / \mathrm{H}$ levels were associated with smaller Mo-V-O grain sizes measured with XRD and lower $\mathrm{V}$ and $\mathrm{Nb}$ uptake into the base catalysts evidenced by EDS. These results suggest that control over product distribution may be afforded through a combination of appropriate catalyst stoichiometry and tuning of grain size. It is clear, however, that a large displacement of $\mathrm{V}$ from the Mo-V-O structure is unfavorable for all value product yields, as this was observed to the greatest extent for high doping levels of Pd and Cs, which on average yielded the lowest selectivity towards both acetic acid and ethylene. This is consistent with the role of vanadia as a catalytically active center for alkane activation and olefin production $[9,52,53]$.

In fact, the presence of Cs was detrimental to both ethylene and AA formation for all redox elements at all $\mathrm{D} / \mathrm{H}$ and $\mathrm{R} / \mathrm{A}$ levels, leading to the formation of almost exclusively total oxidation products. This is likely because Cs disrupts the structural integrity of the host, as evidenced by the formation of secondary phases visible in XRD. As the primary Mo-V-O phase, hallmarked by the characteristic $22^{\circ} \mathrm{XRD}$ peak, has been attributed to the preferential oxidation towards olefins and acids [20,54], it is reasonable to assume that the destabilization of this phase and secondary-phase formation induced by Cs would negatively affect activity through the loss of AA and ethylene-selective sites or formation of combustion sites. This type of structural disturbance induced by dopant addition to the base Mo-V-O structure is markedly different from that observed by others, where activity has been found to increase with increased dopant concentrations accompanied by higher defect densities 
and more polydisperse crystallites [24]. Additionally, decreased activity can also be attributed to a disruption of the crystalline M1/M2 structure, which can hinder lattice oxygen mobility that results in a loss in selectivity towards acids and olefins from alkane oxidation $[22,36,55]$. The difference in the observed structural effect is possibly due to the very large atomic radius of Cs in comparison to other dopants studied.

To address the finding that the doped $\mathrm{MoVNb}$ reached different levels of conversion at $450{ }^{\circ} \mathrm{C}$, the catalysts were compared according to their ethylene and acetic acid selectivity as a function of conversion, as shown in Figure 9. Catalysts are labeled by their standard orders according to the $3^{4}$ full factorial design. The corresponding factorial design levels (dopants and loadings) for each design point are shown in Table 1 of the supporting info. To understand how changing the conversion level changed the selectivity of the most promising materials, the optimum catalysts were compared at different conversions achieved by ramping the catalyst bed temperature in the range of $250-550{ }^{\circ} \mathrm{C}$. Optimum catalysts were defined as those samples that reached the highest AA or ethylene selectivity at the highest possible ethane conversions at $450{ }^{\circ} \mathrm{C}$, as shown in Figure 7 . The ethylene and acetic acid selectivity of the selected catalysts at varied conversions are shown in Figure 10. In general, ethylene selectivity decreased with increased conversion, corresponding to higher bed temperatures, while acetic acid selectivity increased. For most catalysts, acetic acid selectivity was maximized at conversions $>80 \%$, while ethylene selectivity was maximized at conversions $<20 \%$. While kinetic understanding of the system is convoluted at high conversion, we chose to maximize the total yield of acetic acid by optimizing the system for high conversion and high acetic selectivity, shown in Figure 9.
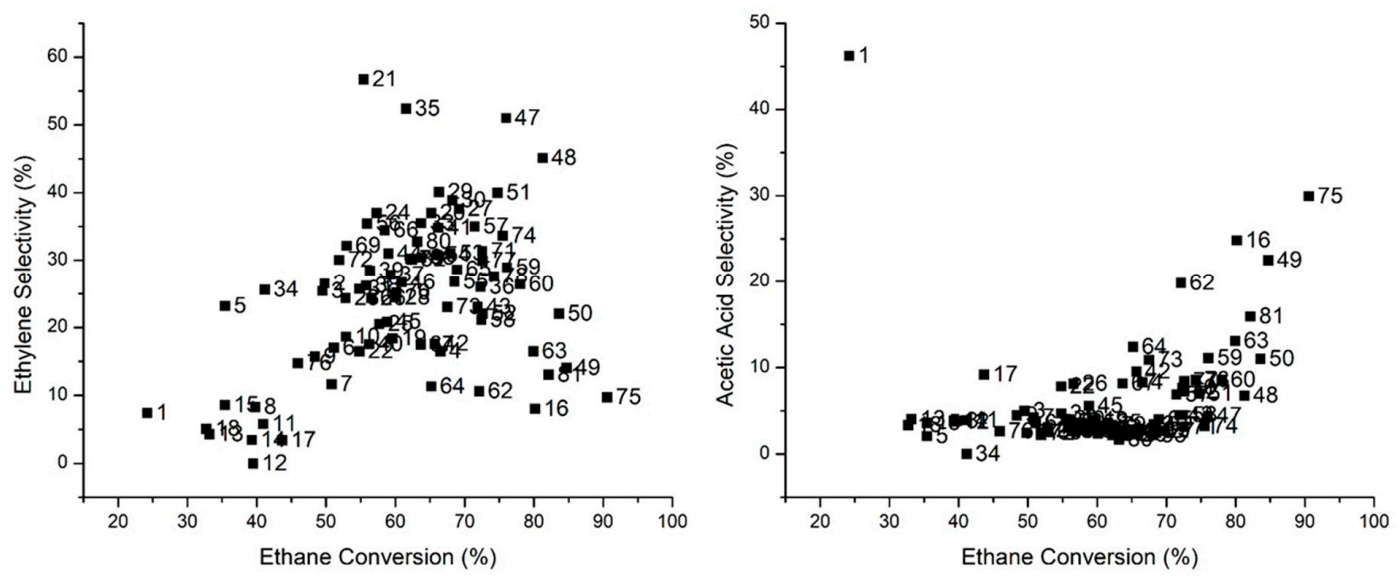

Figure 9. Ethylene and acetic acid selectivity vs. conversion for all samples at $450{ }^{\circ} \mathrm{C}$.
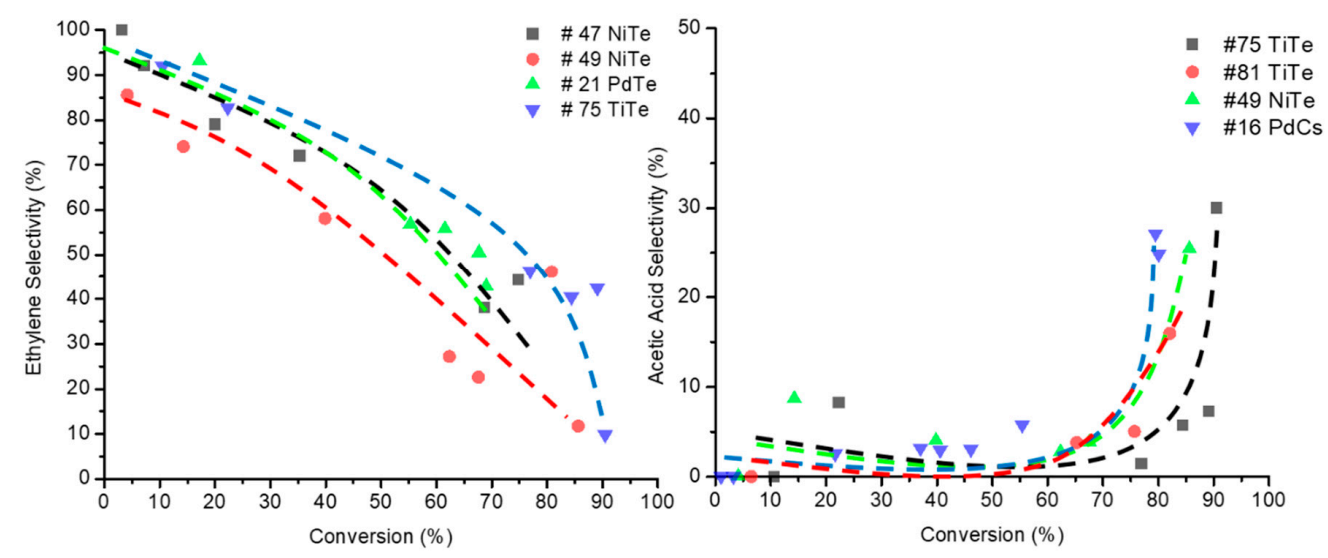

Figure 10. Ethylene and acetic acid selectivity vs. ethane conversion for optimum catalysts. 


\section{Experimental Methods}

\subsection{Catalyst Synthesis}

A typical catalyst composition was synthesized using $4.03 \mathrm{~g}$ ammonium molybdate tetrahydrate (Sigma-Aldrich, St. Louis, $\mathrm{MO}$, USA, $81-83 \% \mathrm{MoO}_{3}$ basis) mixed with $0.88 \mathrm{~g}$ ammonium niobate (V) oxalate hydrate (Sigma-Aldrich, St. Louis, MO, USA, 99.95\%) in $60 \mathrm{~mL}$ of deionized water (DI water) while heating to $50{ }^{\circ} \mathrm{C}$ to ensure complete solvation of the precursors. The vanadium precursor was prepared in a separate container consisting of $1.73 \mathrm{~g}$ of vanadium oxide sulfate (Sigma-Aldrich, St. Louis, MO, USA, $97 \%$ ) in $15 \mathrm{~mL}$ of DI water at $50{ }^{\circ} \mathrm{C}$. Dopants were added before mixing the base catalyst components via stock solutions of either ammonium tetrachloropalladate (Sigma-Aldrich, St. Louis, MO, USA, 97\%), titanium sulfate solution (Sigma-Aldrich, St. Louis, MO, USA, 99.9\%), nickel sulfate (Sigma-Aldrich, St. Louis, MO, USA, 99.99\%), cesium sulfate (Sigma-Aldrich, St. Louis, MO, USA, 99.99\%), telluric acid (Sigma-Aldrich, St. Louis, MO, USA, 98\%), and potassium sulfate (Sigma-Aldrich, St. Louis, MO, USA, 99\%), prepared via dissolving the precursor salts in DI water. After addition of the required amount of dopant, the molybdenum/niobium and vanadium solution were added to the dopant mixture and allowed to mix for $20 \mathrm{~min}$ under stirring. The mixed precursors were then transferred into Teflon liners and set in autoclaves to carry out the hydrothermal synthesis at $175^{\circ} \mathrm{C}$ for $48 \mathrm{~h}$. Upon completion of the hydrothermal synthesis, the catalyst was washed with water and acetone to ensure only the precipitated product was recovered, after which the washed catalyst was set to dry at $120^{\circ} \mathrm{C}$ for $2 \mathrm{~h}$ followed by calcination at $400{ }^{\circ} \mathrm{C}$ for 4 hours in air using a $10{ }^{\circ} \mathrm{C}$ ramp rate for heating and cooling. Synthesis of the base catalyst was carried out following the same steps without the addition of dopants.

\section{2. $X R D$}

X-ray diffraction was carried out for all samples in a Rigaku Miniflex II (Tokyo, Japan) equipped with a $\mathrm{Cu}-\mathrm{K} \alpha \mathrm{X}$-ray source and a high-speed silicon-strip detector. Scans were completed between a 10 and $90^{\circ} 2 \theta$ angle at a rate of $2^{\circ} / \mathrm{min}$ with step size of $0.02^{\circ}$.

\subsection{Scanning Electron Microscopy/EDS (SEM/EDS)}

To confirm elemental uptakes and identify unintended variations in loadings, SEM/EDS characterization was performed on all 81 samples using a Zeiss Ultraplus Thermal Field Emission Scanning Electron Microscope (Carl Zeiss, Oberkochen, Germany) at $15 \mathrm{keV}$. Atomic percentage data were collected over three unique regions of each sample selected from SEM micrographs to provide average atomic compositions as well as measurement error. The atomic composition of each component was scaled to $\mathrm{Mo}=8$ to omit the presence of oxygen and carbon from the measurements. This constraint necessarily defined the error in Mo loading to equal zero.

\subsection{Catalytic Activity Tests}

Ethane partial oxidation tests were performed using an ethane to oxygen ratio of 4:5 [16,50] ( $40 \%$ ethane, $50 \%$ oxygen, $10 \%$ nitrogen). Onstream results were analyzed with a Shimadzu Gas Chromatograph GC2014 (Kyoto, Japan), equipped with a thermal conductivity detector (TCD) to analyze the product distribution. The experiments were carried out in a quartz tube plug flow reactor at ambient pressure, where the space velocity was kept at a constant $1200 \mathrm{~h}^{-1}$. Catalysts were sieved between 45 and 60 mesh size to mitigate a pressure drop. The catalysts were used as synthesized and a temperature ramp in the range of $120-460^{\circ} \mathrm{C}$ was used with an initial $10^{\circ} \mathrm{C} / \mathrm{min}$ ramp rate from room temperature to $120^{\circ} \mathrm{C}$, and a subsequent $30^{\circ} \mathrm{C}$ step size $\left(1.5^{\circ} \mathrm{C} / \mathrm{min}\right.$ rate) for each catalyst was applied. Temperature measurements were taken inside the catalyst bed using an insulated K-type thermocouple. 


\section{Conclusions}

In our studies, the optimal catalyst compositions for ethane partial oxidation to both acetic acid and ethylene with regards to the addition of redox and acid dopants to a base $\mathrm{Mo}_{8} \mathrm{~V}_{2} \mathrm{Nb}_{1}$ catalyst were identified. A DOE methodology was implemented to gain statistically significant insights on the impact of tuning the balance between the acidity and redox behavior of the catalyst via the addition of the selected dopants and to identify useful trends to aid the design of mixed metal oxide EPO catalysts in the future. Analysis was carried out to correlate the redox-element loading $(\mathrm{Pd}, \mathrm{Ni}$, or $\mathrm{Ti})$ and acid-element loading $(\mathrm{K}, \mathrm{Cs}$, or Te) with the catalytic performance and structural integrity of the materials. It was found that across all catalyst compositions explored, an excess of surface acidity relative to the redox element ( $\mathrm{R} / \mathrm{A}$ ratio of 0.005 ) benefited both ethylene and acetic acid formation. Additionally, investigation of the total dopant level $(\mathrm{D} / \mathrm{H}$ ratio) led to the finding that doping high levels of Ti optimized the selectivity for both AA and ethylene, while doping high levels of $\mathrm{Ni}$ and $\mathrm{Pd}$ led to the formation of combustion products. Overall, AA production was favored with TiTe doping while ethylene production was favored with NiTe doping. Additionally, it was found that Cs-doped catalysts ubiquitously favored ethane combustion. The effects of dopant composition on the catalyst structure were elucidated, where the extent of phase segregation and incorporation of dopants into the base catalyst was most sensitive to the acid/base element doped, and the incorporation of cesium was found to trigger the formation of multiple secondary phases. Overall, tuning the balance between redox and acid elements doped into $\mathrm{Mo}_{8} \mathrm{~V}_{2} \mathrm{Nb}_{1}$ catalysts resulted in not only changes to the surface acidity and redox properties, but also induced a change in the bulk catalyst structure, the coupled effects of which were found to ultimately determine the materials' catalytic properties.

Supplementary Materials: The following are available online at http://www.mdpi.com/2073-4344/8/9/370/s1.

Author Contributions: Conceptualization of the work by J.D.J., C.W., and J.L. Methodology and data analysis by J.D.J., T.B., and K.M. Manuscript-writing and editing by J.D.J. and K.M. Project administration and supervision by C.W. and J.L.

Funding: The authors acknowledge financial support from the National Science Foundation, grant IIP 1464630, and the South Carolina Smartstate Center for Strategic Approaches to the Generation of Electricity.

Conflicts of Interest: The authors declare no conflict of interest.

\section{References}

1. Banares, M.A. Supported metal oxide and other catalysts for ethane conversion: A review. Catal. Today 1999, 51, 319-348. [CrossRef]

2. Cavani, F.; Ballarini, N.; Cericola, A. Oxidative dehydrogenation of ethane and propane: How far from commercial implementation? Catal. Today 2007, 127, 113-131. [CrossRef]

3. Brik, Y.; Kacimi, M.; Ziyad, M.; Bozon-Verduraz, F. Titania-supported cobalt and cobalt-phosphorus catalysts: Characterization and performances in ethane oxidative dehydrogenation. J. Catal. 2001, 202, 118-128. [CrossRef]

4. Cimino, S.; Donsì, F.; Russo, G.; Sanfilippo, D. Olefins production by catalytic partial oxidation of ethane and propane over Pt/ $\mathrm{LaMnO}_{3}$ catalyst. Catal. Today 2010, 157, 310-314. [CrossRef]

5. Le Bars, J.; Auroux, A.; Forissier, M.; Vedrine, J. Active sites of $\mathrm{V}_{2} \mathrm{O}_{5} / \gamma-\mathrm{Al}_{2} \mathrm{O}_{3}$ catalysts in the oxidative dehydrogenation of ethane. J. Catal. 1996, 162, 250-259. [CrossRef]

6. Bodke, A.; Olschki, D.; Schmidt, L.; Ranzi, E. High selectivities to ethylene by partial oxidation of ethane. Science 1999, 285, 712-715. [CrossRef] [PubMed]

7. Michael, B.C.; Nare, D.N.; Schmidt, L.D. Catalytic partial oxidation of ethane to ethylene and syngas over rh and pt coated monoliths: Spatial profiles of temperature and composition. Chem. Eng. Sci. 2010, 65, 3893-3902. [CrossRef]

8. Bergh, S.; Guan, S.; Hagemeyer, A.; Lugmair, C.; Turner, H.; Volpe, A.F.; Weinberg, W.H.; Mott, G. Gas phase oxidation of ethane to acetic acid using high-throughput screening in a massively parallel microfluidic reactor system. Appl. Catal. A 2003, 254, 67-76. [CrossRef] 
9. Rahman, F.; Loughlin, K.F.; Al-Saleh, M.A.; Saeed, M.R.; Tukur, N.M.; Hossain, M.M.; Karim, K.; Mamedov, A. Kinetics and mechanism of partial oxidation of ethane to ethylene and acetic acid over mov type catalysts. Appl. Catal. A 2010, 375, 17-25. [CrossRef]

10. Roussel, M.; Barama, S.; Löfberg, A.; Al-Sayari, S.; Karim, K.; Bordes-Richard, E. Mov-based catalysts in ethane oxidation to acetic acid: Influence of additives on redox chemistry. Catal. Today 2009, 141, 288-293. [CrossRef]

11. Tessier, L.; Bordes, E.; Gubelmann-Bonneau, M. Active specie on vanadium-containing catalysts for the selective oxidation of ethane to acetic acid. Catal. Today 1995, 24, 335-340. [CrossRef]

12. Li, X.; Iglesia, E. Kinetics and mechanism of ethane oxidation to acetic acid on catalysts based on Mo- $\mathrm{V}-\mathrm{Nb}$ oxides. J. Phys. Chem. C 2008, 112, 15001-15008. [CrossRef]

13. Botella, P.; Dejoz, A.; Nieto, J.L.; Concepcion, P.; Vázquez, M. Selective oxidative dehydrogenation of ethane over movsbo mixed oxide catalysts. Appl. Catal. A 2006, 298, 16-23. [CrossRef]

14. Botella, P.; Garcı-González, E.; Dejoz, A.; Nieto, J.L.; Vázquez, M.; González-Calbet, J. Selective oxidative dehydrogenation of ethane on movtenbo mixed metal oxide catalysts. J. Catal. 2004, 225, 428-438. [CrossRef]

15. Botella, P.; Nieto, J.L.; Solsona, B.; Mifsud, A.; Márquez, F. The preparation, characterization, and catalytic behavior of movtenbo catalysts prepared by hydrothermal synthesis. J. Catal. 2002, 209, 445-455. [CrossRef]

16. Ruth, K.; Kieffer, R.; Burch, R. Mo-V-Nb oxide catalysts for the partial oxidation of ethane: I. Preparation and structural characterisation. J. Catal. 1998, 175, 16-26. [CrossRef]

17. Li, X.; Iglesia, E. Support and promoter effects in the selective oxidation of ethane to acetic acid catalyzed by Mo-V-Nb oxides. Appl. Catal. A 2008, 334, 339-347. [CrossRef]

18. Chen, N.F.; Ueda, W.; Oshihara, K. Hydrothermal synthesis of Mo-V-M-O complex metal oxide catalysts active for partial oxidation of ethane. Chem. Commun. 1999, 517-518. [CrossRef]

19. Chen, N.F.; Oshihara, K.; Ueda, W. Selective oxidation of ethane over hydrothermally synthesized Mo-V-Al-Ti oxide catalyst. Catal. Today 2001, 64, 121-128. [CrossRef]

20. Thorsteinson, E.; Wilson, T.; Young, F.; Kasai, P. The oxidative dehydrogenation of ethane over catalysts containing mixed oxides of molybdenum and vanadium. J. Catal. 1978, 52, 116-132. [CrossRef]

21. Oshihara, K.; Nakamura, Y.; Sakuma, M.; Ueda, W. Hydrothermal synthesis of novel crystalline Mo-V-M-O $(\mathrm{M}=\mathrm{Al}, \mathrm{Ga}, \mathrm{Fe})$ mixed oxide in the presence of triethylammonium chloride and their catalytic performance for selective ethane oxidation. Catal. Today 2001, 71, 153-159. [CrossRef]

22. Linke, D.; Wolf, D.; Baerns, M.; Timpe, O.; Schlögl, R.; Zey $\beta$, S.; Dingerdissen, U. Catalytic partial oxidation of ethane to acetic acid over $\mathrm{Mo}_{1} \mathrm{~V}_{0.25} \mathrm{Nb}_{0.12} \mathrm{Pd}_{0.0005} \mathrm{O}_{x}$ : I. Catalyst performance and reaction mechanism. J. Catal. 2002, 205, 16-31. [CrossRef]

23. Valente, J.S.; Quintana-Solórzano, R.; Armendáriz-Herrera, H.; Barragán-Rodríguez, G.; López-Nieto, J. Kinetic study of oxidative dehydrogenation of ethane over movtenb mixed-oxide catalyst. Ind. Eng. Chem. Res. 2013, 53, 1775-1786. [CrossRef]

24. Ishchenko, E.; Kardash, T.Y.; Gulyaev, R.; Ishchenko, A.; Sobolev, V.; Bondareva, V. Effect of k and Bi doping on the M1 phase in MoVTeNbO catalysts for ethane oxidative conversion to ethylene. Appl. Catal. A 2016, 514, 1-13. [CrossRef]

25. Ueda, W.; Oshihara, K. Selective oxidation of light alkanes over hydrothermally synthesized Mo-V-M-O (M = Al, Ga, Bi, Sb, and Te) oxide catalysts. Appl. Catal. A 2000, 200, 135-143. [CrossRef]

26. Nguyen, T.; Aouine, M.; Millet, J. Optimizing the efficiency of movtenbo catalysts for ethane oxidative dehydrogenation to ethylene. Catal. Commun. 2012, 21, 22-26. [CrossRef]

27. Valente, J.S.; Armendáriz-Herrera, H.C.; Quintana-Solórzano, R.; Del Angel, P.; Nava, N.; Massó, A.; López Nieto, J.M. Chemical, structural, and morphological changes of a MoVTeNb catalyst during oxidative dehydrogenation of ethane. ACS Catal. 2014, 4, 1292-1301. [CrossRef]

28. Grasselli, R.K.; Buttrey, D.J.; Burrington, J.D.; Andersson, A.; Holmberg, J.; Ueda, W.; Kubo, J.; Lugmair, C.G.; Volpe, A.F. Active centers, catalytic behavior, symbiosis and redox properties of $\mathrm{MoV}(\mathrm{Nb}, \mathrm{Ta}) \mathrm{Teo}$ ammoxidation catalysts. Top. Catal. 2006, 38, 7-16. [CrossRef]

29. DeSanto, P.; Buttrey, D.J.; Grasselli, R.K.; Lugmair, C.G.; Volpe, A.F.; Toby, B.H.; Vogt, T. Structural aspects of the M1 and M2 phases in MoVNbTeO propane ammoxidation catalysts. Z. Krist-Cryst. Mater. 2004, 219, 152-165. [CrossRef] 
30. Guliants, V.V.; Bhandari, R.; Swaminathan, B.; Vasudevan, V.K.; Brongersma, H.H.; Knoester, A.; Gaffney, A.M.; Han, S. Roles of surface $\mathrm{Te}, \mathrm{Nb}$, and $\mathrm{Sb}$ oxides in propane oxidation to acrylic acid over bulk orthorhombic Mo-V-O phase. J. Phys. Chem. B 2005, 109, 24046-24055. [CrossRef] [PubMed]

31. Heracleous, E.; Lemonidou, A. $\mathrm{Ni}-\mathrm{Nb}-\mathrm{O}$ mixed oxides as highly active and selective catalysts for ethene production via ethane oxidative dehydrogenation. Part I: Characterization and catalytic performance. J. Catal. 2006, 237, 162-174. [CrossRef]

32. Sadakane, M.; Yamagata, K.; Kodato, K.; Endo, K.; Toriumi, K.; Ozawa, Y.; Ozeki, T.; Nagai, T.; Matsui, Y.; Sakaguchi, N.; et al. Synthesis of orthorhombic Mo-V-Sb oxide species by assembly of pentagonal $\mathrm{Mo}_{6} \mathrm{O}_{21}$ polyoxometalate building blocks. Angew. Chem. 2009, 121, 3840-3844. [CrossRef]

33. Hibst, H.; Rosowski, F.; Cox, G. New cs-containing Mo-V ${ }^{4+}$ based oxides with the structure of the $\mathrm{m} 1$ phase-base for new catalysts for the direct alkane activation. Catal. Today 2006, 117, 234-241. [CrossRef]

34. Weirich, T.E.; Portillo, J.; Cox, G.; Hibst, H.; Nicolopoulos, S. Ab initio determination of the framework structure of the heavy-metal oxide $\mathrm{Cs}_{x} \mathrm{Nb}_{2.54} \mathrm{~W}_{2.46} \mathrm{O}_{14}$ from $100 \mathrm{kv}$ precession electron diffraction data. Ultramicroscopy 2006, 106, 164-175. [CrossRef] [PubMed]

35. Solsona, B.; Vázquez, M.; Ivars, F.; Dejoz, A.; Concepción, P.; Nieto, J.L. Selective oxidation of propane and ethane on diluted Mo-V-Nb-Te mixed-oxide catalysts. J. Catal. 2007, 252, 271-280. [CrossRef]

36. Wagner, J.B.; Timpe, O.; Hamid, F.A.; Trunschke, A.; Wild, U.; Su, D.S.; Widi, R.K.; Hamid, S.B.A.; Schlögl, R. Surface texturing of $\mathrm{Mo}-\mathrm{V}-\mathrm{Te}-\mathrm{Nb}-\mathrm{O}_{x}$ selective oxidation catalysts. Top. Catal. 2006, 38, 51-58. [CrossRef]

37. Nieto, J.L.; Botella, P.; Vázquez, M.; Dejoz, A. The selective oxidative dehydrogenation of ethane over hydrothermally synthesised movtenb catalysts. Chem. Commun. 2002, 1906-1907. [CrossRef]

38. López-Medina, R.; Sobczak, I.; Golinska-Mazwa, H.; Ziolek, M.; Bañares, M.A.; Guerrero-Pérez, M.O. Spectroscopic surface characterization of movnbte nanostructured catalysts for the partial oxidation of propane. Catal. Today 2012, 187, 195-200. [CrossRef]

39. Li, X.; Iglesia, E. Synergistic effects of $\mathrm{TiO} 2$ and palladium-based Cocatalysts on the selective oxidation of ethene to acetic acid on Mo-V-Nb oxide domains. Angew. Chem. Int. Ed. 2007, 46, 8649-8652. [CrossRef] [PubMed]

40. Linke, D.; Wolf, D.; Baerns, M.; Zeyß, S.; Dingerdissen, U. Catalytic partial oxidation of ethane to acetic acid over $\mathrm{Mo}_{1} \mathrm{~V}_{0.25} \mathrm{Nb}_{0.12} \mathrm{Pd}_{0.0005} \mathrm{O}_{x}$ : II. Kinetic modelling. J. Catal. 2002, 205, 32-43. [CrossRef]

41. Schuurman, Y.; Ducarme, V.; Chen, T.; Li, W.; Mirodatos, C.; Martin, G. Low temperature oxidative dehydrogenation of ethane over catalysts based on group viii metals. Appl. Catal. A 1997, 163, 227-235. [CrossRef]

42. Zhang, X.; Liu, J.; Jing, Y.; Xie, Y. Support effects on the catalytic behavior of $\mathrm{NiO} / \mathrm{Al}_{2} \mathrm{O}_{3}$ for oxidative dehydrogenation of ethane to ethylene. Appl. Catal. A 2003, 240, 143-150. [CrossRef]

43. Heracleous, E.; Lemonidou, A. Ni-Nb-O mixed oxides as highly active and selective catalysts for ethene production via ethane oxidative dehydrogenation. Part II: Mechanistic aspects and kinetic modeling. J. Catal. 2006, 237, 175-189. [CrossRef]

44. Amakawa, K.; Kolen'ko, Y.V.; Villa, A.; Schuster, M.E.; Csepei, L.-I.; Weinberg, G.; Wrabetz, S.; Naumann d'Alnoncourt, R.; Girgsdies, F.; Prati, L. Multifunctionality of crystalline MoV (TeNb) M1 oxide catalysts in selective oxidation of propane and benzyl alcohol. ACS Catal. 2013, 3, 1103-1113. [CrossRef]

45. Sopa, M.; Wacław-Held, A.; Grossy, M.; Pijanka, J.; Nowińska, K. Ethane to acetic acid oxidation over supported heteropoly acids. Appl. Catal. A 2005, 285, 119-125. [CrossRef]

46. Grasselli, R.K.; Buttrey, D.J.; DeSanto, P., Jr.; Burrington, J.D.; Lugmair, C.G.; Volpe, A.F., Jr.; Weingand, T. Active centers in $\mathrm{Mo}-\mathrm{V}-\mathrm{Nb}-\mathrm{Te}-\mathrm{O}_{\mathrm{x}}(\mathrm{amm})$ oxidation catalysts. Catal. Today 2004, 91, 251-258. [CrossRef]

47. Holmberg, J.; Grasselli, R.K.; Andersson, A. Catalytic behaviour of M1, M2, and M1/M2 physical mixtures of the Mo-V-Nb-Te-oxide system in propane and propene ammoxidation. Appl. Catal. A 2004, 270, 121-134. [CrossRef]

48. Azaroff, L.V.; Buerger, M.J. Analytical methods for indexing powder photographs. In The powder method in x-ray crystallography; The Maple Press Company: York, PA, USA, 1958; Volume 1, pp. 79-90.

49. Henry, N.F.; Wooster, W.A.; Lipson, H. Measurements of crystal grain size in polycrystalline aggregates. In The interpretation of $x$-ray diffraction photographs; Macmillan: London, UK, 1951; Volume 1, pp. 212-230.

50. Karim, K.; Mamedov, A.; Al-Hazmi, M.H.; Al-Andis, N. Oxidative dehydrogenation of ethane over MoVMnW oxide catalysts. React. Kinet. Catal. Lett. 2003, 80, 3-11. [CrossRef] 
51. Oyama, S.T. Adsorbate bonding and the selection of partial and total oxidation pathways. J. Catal. 1991, 128, 210-217. [CrossRef]

52. Zhao, Z.; Gao, X.; Wachs, I.E. Comparative study of bulk and supported V-Mo-Te-Nb-O mixed metal oxide catalysts for oxidative dehydrogenation of propane to propylene. J. Phys. Chem. B 2003, 107, 6333-6342. [CrossRef]

53. Hävecker, M.; Wrabetz, S.; Kröhnert, J.; Csepei, L.-I.; d'Alnoncourt, R.N.; Kolen'ko, Y.V.; Girgsdies, F.; Schlögl, R.; Trunschke, A. Surface chemistry of phase-pure M1 MoVTeNb oxide during operation in selective oxidation of propane to acrylic acid. J. Catal. 2012, 285, 48-60. [CrossRef]

54. Chen, C.; Kosuke, N.; Murayama, T.; Ueda, W. Single-crystalline-phase mo3vox: An efficient catalyst for the partial oxidation of acrolein to acrylic acid. Chem CatChem 2013, 5, 2869-2873. [CrossRef]

55. Wagner, J.B.; Hamid, S.A.; Othman, D.; Timpe, O.; Knobl, S.; Niemeyer, D.; Su, D.S.; Schlögl, R. Nanostructuring of binary molybdenum oxide catalysts for propene oxidation. J. Catal. 2004, 225, 78-85. [CrossRef] 